\title{
DESINFESTAÇÃO E GERMINAÇÃO IN VITRO DE SEMENTES DE MOGNO (Swietenia macrophylla King) ${ }^{1}$
}

\author{
Juliana Margarido Fonseca Couto ${ }^{2}$, Wagner Campos Otoni ${ }^{3}$, Antônio Lelis Pinheiro ${ }^{4}$ e Ésio de Pádua \\ Fonseca $^{5}$
}

\begin{abstract}
RESUMO - O presente trabalho teve como objetivos desenvolver técnicas de regeneração in vitro a partir de segmentos de epicótilo, epicótilo invertido e explantes foliares provenientes de plântulas de mogno (Swietenia macrophylla) germinadas em meio de cultura; e determinar a melhor concentração e tempo de exposição das sementes ao agente desinfestante, bem como a melhor posição de semeadura para germinação. As sementes foram desinfestadas, após a retirada do tegumento, em soluções com hipoclorito de sódio nas concentrações de $0 ; 2,5 ;$ e 5,0\% (v/v), mantidas embebidas por 10, 20, 30 e 40 minutos e colocadas no meio em duas posições, sendo a posição 1 com a concavidade da parte achatada voltada para cima e na posição 2 , com a concavidade da parte achatada voltada para baixo. Após a semeadura, foram mantidas em sala de crescimento com temperatura de $\pm 26 \pm 2{ }^{\circ} \mathrm{C}$ e escuro contínuo. O delineamento utilizado foi o inteiramente casualizado, em esquema fatorial 3 x 4 × 2 (níveis de hipoclorito x tempos de embebição x posição de semeadura), totalizando 24 tratamentos com três repetições. As avaliações de germinação e contaminação por microrganismos ocorreram aos 12 , 18, 24 e 30 dias. O melhor tratamento foi a desinfestação das sementes embebidas em 2,5 e 5\% de hipoclorito de sódio por 30 e 20 minutos, respectivamente, as quais foram colocadas na posição 2, pois apresentaram a maior germinação (48\%) e baixa contaminação (15 e 10\%, respectivamente). Quanto à posição, houve diferença significativa aos 24 e 30 dias após a semeadura, com as maiores médias nas sementes colocadas na posição 2 .
\end{abstract}

Palavras-chave: Swietenia macrophylla, mogno, germinação in vitro, desinfestação de sementes, posição de semeadura.

\section{IN VITRO STERILIZATION AND GERMINATION OF MAHOGANY SEEDS (Swietenia macrophylla King) ${ }^{1}$}

\begin{abstract}
The objective of this work was to develop techniques of in vitro regeneration for mahogany (Swietenia macrophylla), using epicotyl segments, inverted epicotyls and leaf explants from mahogany plantlets germinated in culture medium. Also, the best concentration and time and sterilizing agent for seed sterilization were determined, as well as the best seed sowing position for germination. After tegument removal, seeds were sterilized in sodium hipochlorite solution at 0; 2,5 and 5,0\% (v/v) concentrations, kept soaking for 10, 20, 30 and 40 minutes and inoculated in the culture medium in two positions: a) position 1 - with the concavity of the flat part turned upward, and b) position 2 - with the concavity of the flat part turned down. After sowing, seeds were kept in growth room with controlled temperature $\left( \pm 26 \pm 2^{\circ} \mathrm{C}\right)$ and continuous dark. An entirely random factorial design, with $3 \times 4 \times 2$ (sodium hipochlorite levels $x$ soaking times $x$ seed position), totaling 24 treatments with 3 repetitions was used. The germination stage and microorganism contamination were evaluated at 12,18,24 and 30 days after germination. The best treatments were seed sterilization in
\end{abstract}

\footnotetext{
${ }^{1}$ Recebido para publicação em 27.2.2003 e aceito para publicação em 10.8.2004.

${ }^{2}$ Programa de Pós-Graduação em Ciência Florestal da UFV. E-mail: <jmfcouto@ vicosa.ufv.br>.

${ }^{3}$ Departamento de Biologia Vegetal - UFV. E-mail: <wotoni@ufv.br>;

${ }^{4}$ Departamento de Engenharia Florestal - UFV. E-mail: <pinheiro@ufv.br>;

${ }^{5}$ Departamento de Agronomia - UEL. E-mail: <esiof@uel.br>.
} 
2,5 and 5\% sodium hipochlorite for 30 and 20 minutes, respectively, and both inoculated in position 2. These treatment also presented the highest germination rate (48\%) and the lowest rates of microorganism contamination (15 e 10\% respectively). As for position, a significant difference was detected for 24 and 30 days after sowing, with the largest means for seeds inoculated in position 2.

Key words: Swietenia macrophylla, mogno, in vitro germination, seeds sterilization, sowing position

\section{INTRODUÇÃO}

A falta de uma política ambiental mais severa, de conhecimentos técnicos e de consciência ecológica pode levar à exploração desordenada das florestas da Amazônia, com conseqüente diminuição da biodiversidade e perdas de recursos genéticos de espécies com elevados valores econômicos, além de acarretar problemas ambientais, como a redução da cobertura florestal e a destruição dos mananciais hídricos, prejudicando a fauna e a flora, principalmente as espécies com risco de extinção.

O governo brasileiro, reconhecendo o risco de extinção de algumas espécies, entre elas Swietenia macrophylla (mogno), de grande interesse econômico, decretou em 2000 a Lei $\mathrm{n}^{\circ} 3.559$, proibindo a exploração e comercialização da madeira dessa espécie. A proibição é importante para garantir a manutenção de maciços florestais formados pelo mogno e faz com que os técnicos incrementem as pesquisas, a fim de melhorar os conhecimentos de auto-ecologia, sinecologia e meio ambiente aplicáveis aos futuros planos de manejos sustentáveis para a região.

Os pesquisadores têm encontrado dificuldades em estabelecer procedimentos para a propagação in vitro do mogno, considerando-se, em parte, a escassez de trabalhos publicados nessa linha de pesquisa. No entanto, a falta de conhecimento dos principais processos básicos da germinação que ocorrem nas sementes de espécies nativas tem dificultado a realização das metas dos programas de reflorestamento, devido às dificuldades encontradas durante o processo de produção de mudas em viveiro ou laboratório.

As espécies lenhosas apresentam dificuldades para o estabelecimento in vitro, principalmente se for utilizado material vegetal proveniente de plantas adultas, pois podem apresentar infestação interna ou externa por microrganismos. Por isso, a utilização de plântulas germinadas in vitro, em condições assépticas, tornase mais vantajosa (SKIRVIN, 1981). Segundo Corder e Borges Junior (1999), vários fatores podem afetar o vigor germinativo das sementes e promover a formação de plântulas anormais ou sua morte, entre eles a dormência e a presença de microrganismos, sobretudo de fungos e bactérias. Por isso, os métodos de desinfestação devem ser eficazes, para que a plântula sirva de fonte de explante livre de fungos e bactérias.

De acordo com Lopes (2000), a vermiculita foi superior ao ágar como substrato para a germinação de sementes de mogno in vitro, enquanto a eficiência dos métodos de desinfestação e quebra de dormência em sementes de Acacia mearnsii De Wild. e de germinação de sementes de Dalbergia sissoo Roxb. e a propagação através de sementes de Myracrodruon urundeuva Allemão, quando in vitro, para a obtenção de plântulas, são confirmadas por Corder e Borges Junior (1999), Andrade et al. (2000) e Pradhan et al. (1998).

Um fator importante a ser considerado para o aprofundamento das pesquisas direcionadas ao aproveitamento máximo da semente e a obtenção de mudas é a dificuldade de regeneração do mogno, quando manejado sem a técnica adequada ou irracional, causando sua dizimação e conseqüente deficiência de sementes (LOPES, 2000), considerando a rápida perda de viabilidade das sementes após a queda e o período de exposição no solo até o momento da coleta, uma vez que perde $50 \%$ do seu poder germinativo, dependendo do tempo de exposição (MORAES, 2002).

Diante desses fatos, este trabalho teve como objetivo verificar a germinação das sementes de mogno em meio de cultura, determinando a melhor concentração e o tempo de exposição destas ao agente desinfestante, bem como a melhor posição de semeadura.

\section{MATERIAL E MÉTODOS}

O experimento foi desenvolvido no Laboratório de Cultura de Tecidos do BIOAGRO, na Universidade Federal de Viçosa, em Viçosa, MG, no período de agosto de 2001 a janeiro de 2002 . 
As sementes de mogno (Swietenia macrophylla, King) foram coletadas na região de Belém, PA, pela empresa Tramontina Belém S.A.

Para avaliar o efeito dos agentes desinfestantes, as sementes com tegumento foram previamente desinfestadas em hipoclorito de sódio 5\% (v/v) durante 30 minutos. Posteriormente, os tegumentos foram retirados e as sementes, submersas em solução de etanol $70 \%(\mathrm{v} / \mathrm{v})$ por um minuto. A seguir foram embebidas em solução contendo hipoclorito de sódio nas concentrações de $0 ; 2,5 ;$ e 5,0\% (v/v), com três gotas de detergente comercial Tween 20 por $100 \mathrm{ml}$ de solução. Foram então, em seguida, submersas na solução de Benlate na concentração de $1 \mathrm{~g} \mathrm{~L}^{-1} \mathrm{e}$, finalmente, enxaguadas em água destilada autoclavada.

Após a desinfestação, as sementes foram colocadas paralelas ao meio de cultura em meio de cultura em tubos de ensaio em duas posições: posição 1 , com a concavidade da parte achatada voltada para cima, e posição 2, com a concavidade da parte achatada voltada para baixo. Os tratamentos utilizados para desinfestação, tempo de embebição e posição de semeadura das sementes estão relacionados no Quadro 1.

Quadro 1 - Tratamentos utilizados para desinfestação, tempo de embebição e posição de semeadura de sementes de mogno (Swietenia macrophylla)

Table 1 - Treatments used in the sterilization, time of soak and sowing position of mahogany seeds (Swietenia macrophylla)

\begin{tabular}{cccc}
\hline Tratamentos & $\begin{array}{c}\text { Hipoclorito } \\
(\%)\end{array}$ & $\begin{array}{c}\text { Tempo } \\
\text { (minutos) }\end{array}$ & Posição \\
\hline 01 & 0,0 & 10 & 1 \\
02 & 0,0 & 20 & 1 \\
03 & 0,0 & 30 & 1 \\
04 & 0,0 & 40 & 1 \\
05 & 0,0 & 10 & 2 \\
06 & 0,0 & 20 & 2 \\
07 & 0,0 & 30 & 2 \\
08 & 0,0 & 40 & 2 \\
09 & 2,5 & 10 & 1 \\
10 & 2,5 & 20 & 1 \\
11 & 2,5 & 30 & 1 \\
12 & 2,5 & 40 & 1 \\
13 & 2,5 & 10 & 2 \\
14 & 2,5 & 20 & 2 \\
15 & 2,5 & 30 & 2 \\
16 & 2,5 & 40 & 2 \\
17 & 5,0 & 10 & 1 \\
18 & 5,0 & 20 & 1 \\
19 & 5,0 & 30 & 1 \\
20 & 5,0 & 40 & 1 \\
21 & 5,0 & 10 & 2 \\
22 & 5,0 & 20 & 2 \\
23 & 5,0 & 30 & 2 \\
24 & 5,0 & 40 & 2 \\
\hline
\end{tabular}

O delineamento utilizado foi o inteiramente casualizado, em esquema fatorial $3 \times 4 \times 2$ (níveis de hipoclorito de sódio $\mathrm{x}$ tempos de embebição $\mathrm{x}$ posições de semeadura), totalizando 24 tratamentos, com três repetições cada um. Em cada repetição foram utilizadas sete sementes, num total de 504 sementes.

As avaliações das contaminações por fungos e bactérias ocorreram aos 12, 18, 24 e 30 dias após a semeadura das sementes.

Para avaliar o potencial de germinação, após a desinfestação as sementes foram colocadas em meio de cultura composto por sais básicos de MS (MURASHIGE SKOOG, 1962), suplementado com ocomplexo vitamínico MS, $100 \mathrm{~g} \mathrm{~L}^{-1}$ de mioinositol, $2 \%(\mathrm{p} / \mathrm{v}) \mathrm{de}$ sacarose e $0,5 \%(\mathrm{p} / \mathrm{v})$ de ágar (Merck), sendo o pH ajustado em $5,7 \pm 0,1$. Foram vertidos $10 \mathrm{ml}$ do meio de cultura antes da autoclavagem, em cada um dos tubos de ensaio de $25 \times 150 \mathrm{~mm}$.

Logo após a semeadura das sementes, os tubos de ensaio foram transferidos para sala de crescimento e mantidos no escuro à temperatura de $26 \pm 2{ }^{\circ} \mathrm{C}$ até os 30 dias após a semeadura.

A germinação foi avaliada aos 12, 18, 24 e 30 dias após a semeadura. As médias das porcentagens de germinação foram comparadas pelo teste de Tuckey a 5\%, após terem sido transformadas em arco-seno $\sqrt{\% \text { germinação/100 }}$.

\section{RESULTADOS E DISCUSSÃO}

\subsection{Desinfestação in vitro das sementes de Swietenia macrophylla King}

A variação dos dados da eficiência dos tratamentos de desinfestação das sementes de mogno, em relação à formação e desenvolvimento de microrganismos como bactérias e fungos realizados aos 12, 18, 24 e 30 dias após a semeadura, é mostrada nos Quadros 2 e 3 .

Os tratamentos que proporcionaram as menores médias de contaminação por bactéria $(9,52 \%)$ foram aqueles em que as sementes foram desinfestadas com $2,5 \%$ de hipoclorito de sódio, durante 10 e 30 minutos de embebição, e colocadas na posição 2 .

Resultados similares foram obtidos com 5,0\% hipoclorito de sódio durante 20 e 30 minutos de embebição, com as sementes colocadas nas posições 1 e 2 , res-

R. Árvore, Viçosa-MG, v.28, n.5, p.633-642, 2004 
pectivamente, seguidos dos tratamentos em que as sementes foram embebidas em $2,5 \%$ de hipoclorito de sódio, durante 30 e 40 minutos, e colocadas na posição 2, com 14,29\% de sementes infectadas.

Os piores resultados foram obtidos com os tratamentos em que as sementes não receberam a desinfestação com hipoclorito de sódio, apresentando as maiores taxas de contaminação por bactérias com 89 e $67 \%$, principalmente quando mantidas em embebição por 10 e 40 minutos e colocadas nas posições 1 e 2, respectivamente. A segunda maior taxa de contaminação foi observada nas sementes que não receberam a desinfestação com hipoclorito de sódio e foram embebidas em água pura por 40 minutos e colocadas na posição 1 ( $56 \%$ de contaminação).

O resultado deste estudo está de acordo com o de Andrade et al. (2000), que desinfestaram sementes de Myracrodruon urundeuva em álcool $70 \%$ por 30 segundos, seguido de hipoclorito de sódio $1 \%$ por
10 minutos, e as lavaram três vezes com água destilada, as quais não apresentaram nenhum tipo de contaminante.

Carvalho (1994) verificou $65 \%$ de germinação de sementes de aroeira germinadas in vitro que não passaram por qualquer tratamento envolvendo álcool e hipoclorito de sódio. No geral, ocorreram $18 \%$ de contaminação das sementes aos 30 dias após a semeadura em todos os tratamentos que receberam ou não a desinfestação visando ao controle fúngico. Parte dessa contaminação fúngica pode ter ocorrido durante a fase de preparo e manipulação dos materiais ou devido ao fato de as tampas dos tubos de ensaio não permanecerem hermeticamente fechadas durante o período de avaliação. Além disso, segundo Faiad et al. (1997), os fungos associados às sementes podem deteriorálas e ocasionar sua morte, considerando ainda que os testes de germinação e a formação de mudas podem ficar comprometidos por causa da ação de agentes patogênicos e saprófitas conduzidos pela semente.

Quadro 2 - Porcentagem de sementes de Swietenia macrophylla contaminadas por bactérias e fungos, aos 12, 18, 24 e 30 dias, de acordo com os tratamentos utilizados.

Table 2 - Averages Swietenia macrophylla seeds contaminated by bacterias and fungus, at 12, 18, 24 and 30 days, at the used treatments

\begin{tabular}{|c|c|c|c|c|c|c|c|c|c|}
\hline \multirow{3}{*}{\multicolumn{2}{|c|}{ FONTE DE VARIAÇÃO }} & \multicolumn{8}{|c|}{ Tempo (dias) } \\
\hline & & \multirow{3}{*}{$\frac{12}{11,90}$} & \multicolumn{2}{|c|}{ BACTÉRIAS } & & \multicolumn{2}{|c|}{ FUNGOS } & \multirow[b]{2}{*}{24} & \multirow[b]{2}{*}{30} \\
\hline & & & 18 & 24 & 30 & 12 & 18 & & \\
\hline \multirow[t]{2}{*}{ Hipoclorito } & 0 & & 15,48 & 17,26 & 22,62 & 6,55 & 7,74 & 7,74 & 7,74 \\
\hline & $\begin{array}{l}2,5 \\
5,0\end{array}$ & $\begin{array}{l}16,67 \\
13,69\end{array}$ & $\begin{array}{l}23,81 \\
18,45\end{array}$ & $\begin{array}{l}25,00 \\
24,40\end{array}$ & $\begin{array}{l}26,19 \\
25,60\end{array}$ & $\begin{array}{l}2,38 \\
5,95\end{array}$ & $\begin{array}{l}2,98 \\
5,95\end{array}$ & $\begin{array}{l}2,98 \\
5,95\end{array}$ & $\begin{array}{l}3,57 \\
5,95\end{array}$ \\
\hline Tempo & $\begin{array}{l}10 \\
20 \\
30 \\
40\end{array}$ & $\begin{array}{l}19,84 \\
11,90 \\
13,49 \\
11,11\end{array}$ & $\begin{array}{l}23,81 \\
15,87 \\
20,63 \\
16,67\end{array}$ & $\begin{array}{l}26,19 \\
17,46 \\
24,60 \\
20,63\end{array}$ & $\begin{array}{l}28,57 \\
19,05 \\
26,19 \\
25,40\end{array}$ & $\begin{array}{l}3,97 \\
6,35 \\
4,76 \\
4,76\end{array}$ & $\begin{array}{l}5,56 \\
6,35 \\
5,56 \\
4,76\end{array}$ & $\begin{array}{l}5,56 \\
6,35 \\
5,56 \\
4,76\end{array}$ & $\begin{array}{l}6,35 \\
6,35 \\
5,56 \\
4,76\end{array}$ \\
\hline Posição ${ }^{1}$ & $\begin{array}{l}1 \\
2\end{array}$ & $\begin{array}{l}17,06 \\
11,11\end{array}$ & $\begin{array}{l}23,02 \\
15,48\end{array}$ & $\begin{array}{l}26,59 \\
17,86\end{array}$ & $\begin{array}{l}28,97 \\
20,63\end{array}$ & $\begin{array}{l}5,56 \\
4,37\end{array}$ & $\begin{array}{l}5,56 \\
5,56\end{array}$ & $\begin{array}{l}5,56 \\
5,56\end{array}$ & $\begin{array}{l}5,56 \\
5,95\end{array}$ \\
\hline \multicolumn{2}{|c|}{ MÉDIA GERAL } & 14,09 & 19,25 & 22,22 & 24,80 & 4,96 & 5,56 & 5,56 & 5,75 \\
\hline \multicolumn{10}{|l|}{ TESTE F } \\
\hline \multirow[t]{3}{*}{ Hipoclorito } & Linear & NS & NS & NS & NS & NS & NS & NS & NS \\
\hline & Quadrático & NS & NS & NS & NS & NS & NS & NS & NS \\
\hline & Linear & NS & NS & NS & NS & NS & NS & NS & NS \\
\hline \multirow[t]{2}{*}{ Tempo } & Quadrático & NS & NS & NS & NS & NS & NS & NS & NS \\
\hline & Cúbico & NS & NS & NS & NS & NS & NS & NS & NS \\
\hline \multicolumn{2}{|l|}{ Posição } & NS & $*$ & $*$ & $*$ & NS & NS & NS & NS \\
\hline \multicolumn{2}{|c|}{ Tempo X Hipoclorito } & NS & NS & $*$ & $*$ & NS & NS & NS & NS \\
\hline \multicolumn{2}{|c|}{ Tempo X Posição } & NS & NS & NS & NS & NS & NS & NS & NS \\
\hline \multicolumn{2}{|c|}{ Hipocl. X Posição } & NS & NS & NS & $*$ & NS & NS & NS & NS \\
\hline \multicolumn{2}{|l|}{$\mathrm{CV}(\%)$} & 24,65 & 22,81 & 21,13 & 18,79 & 20,36 & 20,63 & 20,63 & 21,58 \\
\hline
\end{tabular}

$* * \quad(\mathrm{P}<0,01) \mathrm{e} *(\mathrm{P}<0,05)$ 
Quadro 3 - Interação significativa da presença de bactérias entre hipoclorito de sódio e tempo de desinfestação em sementes de Swietenia macrophylla, aos 24 e 30 dias após a semeadura

Table 3 - Significant interaction for bacterias presence between sodium hipochlorite and time of soak for sterilization in Swietenia macrophylla seeds, at 24 and 30 days after sowing

\begin{tabular}{|c|c|c|c|c|c|c|c|c|c|c|c|}
\hline \multirow{3}{*}{\multicolumn{2}{|c|}{ CARACTERÍSTICAS }} & \multicolumn{4}{|c|}{ BAC24 } & \multirow[b]{2}{*}{ MÉDIA } & \multicolumn{4}{|c|}{ BAC30 } & \multirow{3}{*}{$\begin{array}{c}\text { MÉDIA } \\
\text { HIP }\end{array}$} \\
\hline & & \multicolumn{4}{|c|}{ TEMPO (min) } & & \multicolumn{4}{|c|}{ TEMPO (min) } & \\
\hline & & 10 & 20 & 30 & 40 & HIP & 10 & 20 & 30 & 40 & \\
\hline \multirow{3}{*}{ HIPOCLORITO } & 0 & $2,00 \mathrm{aA}$ & $1,17 \mathrm{abA}$ & $0,83 \mathrm{bA}$ & $0,83 \mathrm{aA}$ & 1,2083 & $2,17 \mathrm{aA}$ & $1,33 \mathrm{abA}$ & $1,17 \mathrm{aA}$ & $1,33 \mathrm{aA}$ & 1,500 \\
\hline & 2,5 & $2,16 \mathrm{aA}$ & $1,83 \mathrm{aA}$ & $1,83 \mathrm{abA}$ & $1,17 \mathrm{aA}$ & 1,7500 & $2,17 \mathrm{aA}$ & $2,00 \mathrm{aA}$ & $1,83 \mathrm{aA}$ & $1,67 \mathrm{aA}$ & 1,9175 \\
\hline & 5,0 & $1,33 \mathrm{aA}$ & $0,66 \mathrm{bA}$ & $2,50 \mathrm{aA}$ & $2,33 \mathrm{aA}$ & 1,7083 & $1,67 \mathrm{aA}$ & $0,67 \mathrm{bA}$ & $2,50 \mathrm{aA}$ & $2,33 \mathrm{aA}$ & 1,7925 \\
\hline \multicolumn{2}{|l|}{ MÉDIA } & 1,83 & 1,22 & 1,72 & 1,44 & & 2,00 & 1,33 & 1,83 & 1,78 & \\
\hline
\end{tabular}

Médias seguidas de letras diferentes (maiúsculas na horizontal e minúsculas na vertical) diferem entre si, significativamente, pelo teste de Tukey $(\mathrm{P}<0,05)$.

Foi observado, durante o período da germinação, que as sementes contaminadas por fungos e bactérias não foram capazes de germinar. Esse resultado concorda com os de Corder e Borges Júnior (1999), que, ao germinarem sementes de Acácia mearnsii em condições in vitro, observaram que a presença de fungos e bactérias nas sementes foi o fator principal da ausência de germinação. Porém, segundo Kalil Filho et al. (2000), a utilização de hipoclorito de sódio associado ao tempo de desinfestação na presença e ausência de luz foi considerada eficiente, obtendo $100 \%$ da capacidade de germinação, mesmo quando as sementes apresentavam $11,8 \%$ de contaminação por fungos e bactérias.

Analisando os dados do Quadro 2, pode-se observar que não ocorreram efeitos significativos com relação ao uso do hipoclorito de sódio e tempo de desinfestação na presença de bactérias ou de fungos, aos 12, 18, 24 e 30 dias após a semeadura. Quanto à posição de semeadura das sementes, verificouse efeito significativo em relação à presença e desenvolvimento de bactérias aos 18, 24 e 30 dias após a semeadura, indicando que as maiores médias de sementes infestadas ocorreram nas sementes colocadas na posição 1 .

Observam-se ainda, nesse quadro, as interações significativas entre o tempo de embebição das sementes e a concentração de hipoclorito de sódio na presença e desenvolvimento de bactérias aos 24 e 30 dias após a semeadura, enquanto a interação entre a concentração de hipoclorito de sódio e a posição de semeadura das sementes foi significativa apenas nas bactérias aos 30 dias após a semeadura.

Pode-se inferir que, na presença e desenvolvimento de bactérias aos 24 e 30 dias após a semeadura, os comportamentos das interações entre o tempo de embebição e a concentração de hipoclorito de sódio foram similares (Quadro 2).

Não foram observadas diferenças significativas entre os tempos de embebição nas diferentes concentrações de hipoclorito de sódio (Quadro 4), porém, quando a avaliação desses tempos ocorreu dentro de cada tempo (Quadro 2), foi verificado efeito significativo da concentração do hipoclorito de sódio quando as sementes permaneceram embebidas por 20 e 30 minutos, com maiores médias ocorrendo no tempo de 20 minutos de embebição em hipoclorito de sódio $2,5 \%$ e naquelas mantidas por 30 minutos em hipoclorito de sódio 5,0\%.

Com relação à interação entre a concentração de hipoclorito de sódio e a posição de semeadura das sementes (Quadro 5), verificou-se que, na concentração de $2,5 \%$ de hipoclorito de sódio, a posição 1 apresentou média de infestação de bactérias, aos 30 dias após a semeadura, significativamente superior à da posição 2 .

R. Árvore, Viçosa-MG, v.28, n.5, p.633-642, 2004 
Quadro 4 - Interação significativa do número de sementes germinadas entre hipoclorito de sódio e tempo de embebição utilizados para desinfestação de sementes de Swietenia macrophylla, aos 18 dias após a semeadura

Table 4 - Significant interaction for the number of seeds germinated between sodium hipochlorite and time of soak used for sterilization Swietenia macrophylla seeds, at 18 days after sowing

\begin{tabular}{|c|c|c|c|c|c|c|}
\hline & & \multicolumn{4}{|c|}{$\begin{array}{c}\text { TEMPO DE } \\
\text { EMBEBIÇÃO (min) }\end{array}$} & \multirow[t]{2}{*}{$\begin{array}{c}\text { MÉDIA } \\
\text { HIPOCLORITO }\end{array}$} \\
\hline & & 10 & 20 & 30 & 40 & \\
\hline \multirow{3}{*}{ Hipoclorito } & 0 & 0,00 & 0,00 & 0,00 & 0,00 & 0,00 \\
\hline & 2,5 & 14,29 & 11,90 & 28,57 & 14,29 & 17,26 \\
\hline & 5,0 & 19,05 & 21,43 & 23,81 & 2,38 & 16,67 \\
\hline MÉDIA DO TEMPO & & 11,11 & 11,11 & 17,46 & 5,56 & 0,00 \\
\hline
\end{tabular}

Quadro 5 - Interação significativa da presença de bactérias entre hipoclorito de sódio e posição de semeadura em sementes de Swietenia macrophylla, aos 24 e 30 dias após a semeadura

Picture 5 - Significant interaction for bacterias presence between sodium hipochlorite and sowing position in Swietenia macrophylla seeds, at 24 and 30 days after sowing

\begin{tabular}{|c|c|c|c|c|}
\hline \multicolumn{2}{|c|}{ Bactéria 30 Dias } & \multicolumn{2}{|c|}{ Posição } & \multirow{2}{*}{$\begin{array}{c}\text { Média } \\
\text { Hipoclorito }\end{array}$} \\
\hline & & 1 & 2 & \\
\hline \multirow[t]{3}{*}{ Hipoclorito } & 0 & $1,58 \mathrm{aA}$ & $1,58 \mathrm{aA}$ & 1,58 \\
\hline & 2,5 & $2,58 \mathrm{aA}$ & $1,08 \mathrm{aB}$ & 1,83 \\
\hline & 5,0 & 1,92 aA & 1,67 aA & 1,79 \\
\hline \multicolumn{2}{|c|}{ Média Posição } & 2,03 & 1,44 & \\
\hline
\end{tabular}

Médias seguidas de letras diferentes (maiúsculas na horizontal e minúsculas na vertical) diferem entre si, significativamente, pelo teste de Tukey $(\mathrm{P}<0,05)$.

\subsection{Germinação in vitro de sementes de Swietenia macrophylla}

As maiores porcentagens de germinação das sementes $(48 \%)$ in vitro ocorreram aos 30 dias após a semeadura das sementes do tratamento T15 (desinfestadas com hipoclorito de sódio $2,5 \%$, mantidas embebidas por 30 minutos e colocadas na posição com a parte achatada voltada para baixo, ou seja, posição 2).

Notou-se o mesmo resultado nas sementes desinfestadas com hipoclorito de sódio 5,0\% embebidas por 20 minutos e colocadas na posição 2 (T22), porém, nesse composto, observou-se a máxima germinação apenas aos 30 dias após a semeadura, enquanto as sementes do tratamento T15 germinaram aos 24 dias (Figura 1).

R. Árvore, Viçosa-MG, v.28, n.5, p.633-642, 2004
Os resultados deste trabalho são similares aos obtidos por Parraguirre e Camacho (1992), que constataram germinação máxima das sementes de mogno em condições de viveiro em torno de 24 dias.

Pode-se observar, pelos resultados do Quadro 6 , que o uso dos agentes desinfestantes não promoveu efeito significativo sobre os valores de germinação aos 12 dias após a semeadura, mas aos 18, 24 e 30 dias se verificou efeito quadrático na germinação em razão do aumento da concentração do hipoclorito de sódio (Figura 2). Tais resultados não são similares aos obtidos por Kalil Filho et al. (2000), que conseguiram até $100 \%$ de germinação das sementes de mogno quando desinfestadas em hipoclorito de sódio $1 \%$ por cinco minutos e germinadas in vitro, na ausência de luz.

Lopes (2000) concluiu que as sementes de mogno têm germinação rápida, levando seis dias para germinar. Lemos et al. (1998) obtiveram resultado similar ao semear o mogno in vitro, observando o crescimento das plântulas que atingiram de 40 a $65 \mathrm{~mm}$ em 10 dias.

Corder e Borges Junior (1999), após desinfestarem sementes de Acacia mearnsii em água quente a $80^{\circ} \mathrm{C}$ por três minutos e tratá-las com hipoclorito de sódio comercial $10 \%$ por 10 minutos, após a imersão em álcool por 40 segundos, seguida de três lavagens com água destilada, obtiveram $100 \%$ de germinação, porém 50\% dessas plântulas se mostraram anormais.

Com relação ao tempo de embebição das sementes em hipoclorito de sódio, verificou-se que ocorreu efeito quadrático da germinação apenas aos 18 , 24 e 30 dias após a semeadura (Figura 3). 


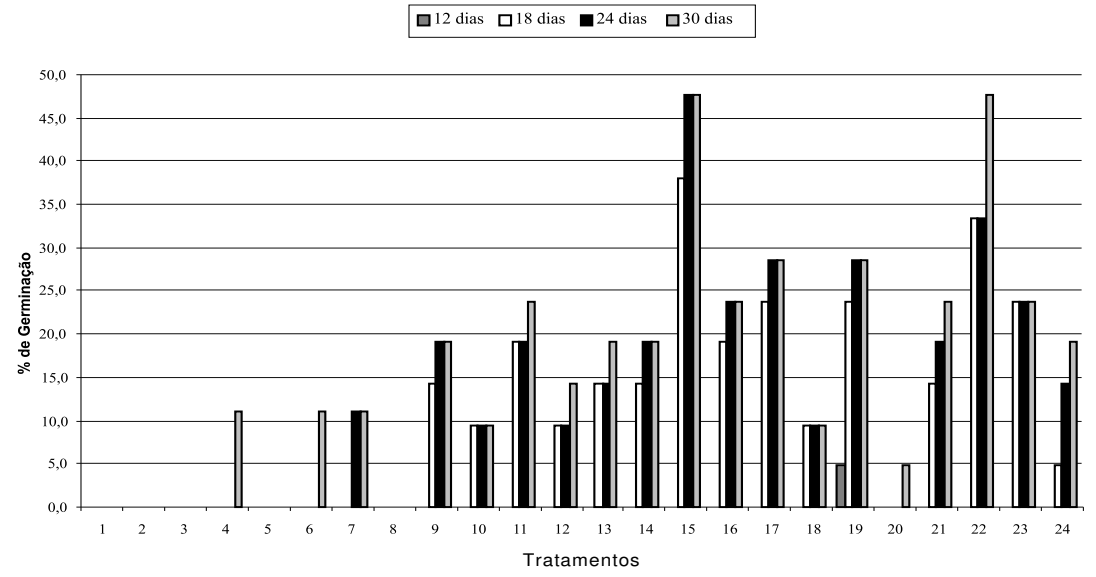

Figura 1 - Porcentagem de germinação in vitro de sementes de Swietenia macrophylla, aos 12, 18, 24 e 30 dias após a semeadura, de acordo com os tratamentos utilizados para desinfestação.

Figure 1 - In vitro germination percentage of Swietenia macrophylla seeds at 12, 18, 24 and 30 days after sowing, in agreement with the treatments used for the desinfestação.

Quadro 6 - Porcentagem de sementes germinadas aos 12,18, 24 e 30 dias após a semeadura das sementes de Swietenia macrophylla King de acordo com os tratamentos utilizados para desinfestação

Table 6 - Averages of the number of seeds germinated at 12,18, 24 and 30 days after the seeds sowing of Swietenia macrophylla King at the treatments used for sterilization.

\begin{tabular}{|c|c|c|c|c|c|}
\hline \multirow{3}{*}{\multicolumn{2}{|c|}{ FONTES DE VARIAÇÃO }} & \multirow{2}{*}{\multicolumn{4}{|c|}{$\begin{array}{c}\text { Tempo (dias) } \\
\% \text { GERMINAÇÃO }\end{array}$}} \\
\hline & & & & & \\
\hline & & \multirow{2}{*}{$\frac{12}{0,0}$} & \multirow{2}{*}{$\begin{array}{l}18 \\
0,0\end{array}$} & \multirow{2}{*}{$\frac{24}{0,6}$} & \multirow{2}{*}{$\begin{array}{l}30 \\
1,8\end{array}$} \\
\hline \multirow{3}{*}{ Hipoclorito } & 0 & & & & \\
\hline & 2,5 & 0,0 & 17,3 & 20,8 & 22,0 \\
\hline & 5,0 & 0,6 & 16,7 & 20,2 & 23,2 \\
\hline \multirow{3}{*}{ Tempo } & 10 & 0,0 & 11,1 & 14,3 & 15,1 \\
\hline & 20 & 0,0 & 11,1 & 11,9 & 15,1 \\
\hline & 30 & 0,8 & 17,5 & 21,4 & 21,4 \\
\hline \multirow{3}{*}{ Posiçãó ${ }^{1}$} & 40 & 0,0 & 5,6 & 7,9 & 11,1 \\
\hline & 1 & 0,4 & 9,1 & 10,7 & 12,3 \\
\hline & 2 & 0,0 & 13,5 & 17,1 & 19,0 \\
\hline MÉDIA GERAL & & 0,2 & 11,3 & 13,9 & 15,7 \\
\hline \multicolumn{6}{|l|}{ TESTE F } \\
\hline \multirow{3}{*}{ Hipoclorito de sódio } & Linear & NS & $* *$ & $* *$ & $* *$ \\
\hline & Quadrático & NS & $* *$ & $* *$ & $* *$ \\
\hline & Linear & NS & NS & NS & NS \\
\hline \multirow[t]{2}{*}{ Tempo } & Quadrático & NS & $*$ & $*$ & NS \\
\hline & Cúbico & NS & $*$ & $* *$ & NS \\
\hline \multicolumn{2}{|l|}{ Posição } & NS & NS & $*$ & * \\
\hline \multicolumn{2}{|l|}{ Tempo X Hipoclorito } & NS & $*$ & NS & NS \\
\hline \multicolumn{2}{|l|}{ Tempo X Posição } & NS & NS & NS & NS \\
\hline \multicolumn{2}{|l|}{ Hipoclorito X Posição } & NS & NS & NS & NS \\
\hline \multicolumn{2}{|l|}{$\mathrm{CV}(\%)$} & 4,85 & 18,04 & 18,15 & 19,56 \\
\hline
\end{tabular}




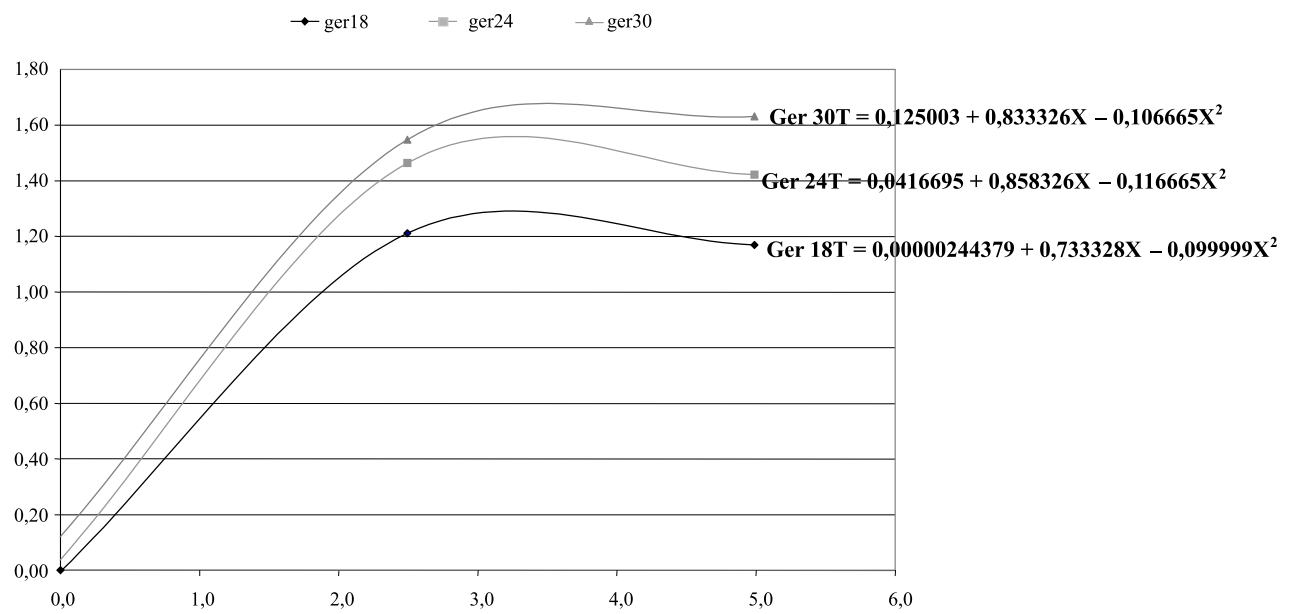

Figura 2 - Médias ajustadas de sementes germinadas de Swietenia macrophylla, aos 18, 24 e 30 dias após a semeadura, em função da concentração de hipoclorito de sódio.

Figure 2-Adjusted averages of germinated seeds of Swietenia macrophylla, at 18, 24 and 30 days after sowing, in function of the concentration of hipoclorito of sodium.

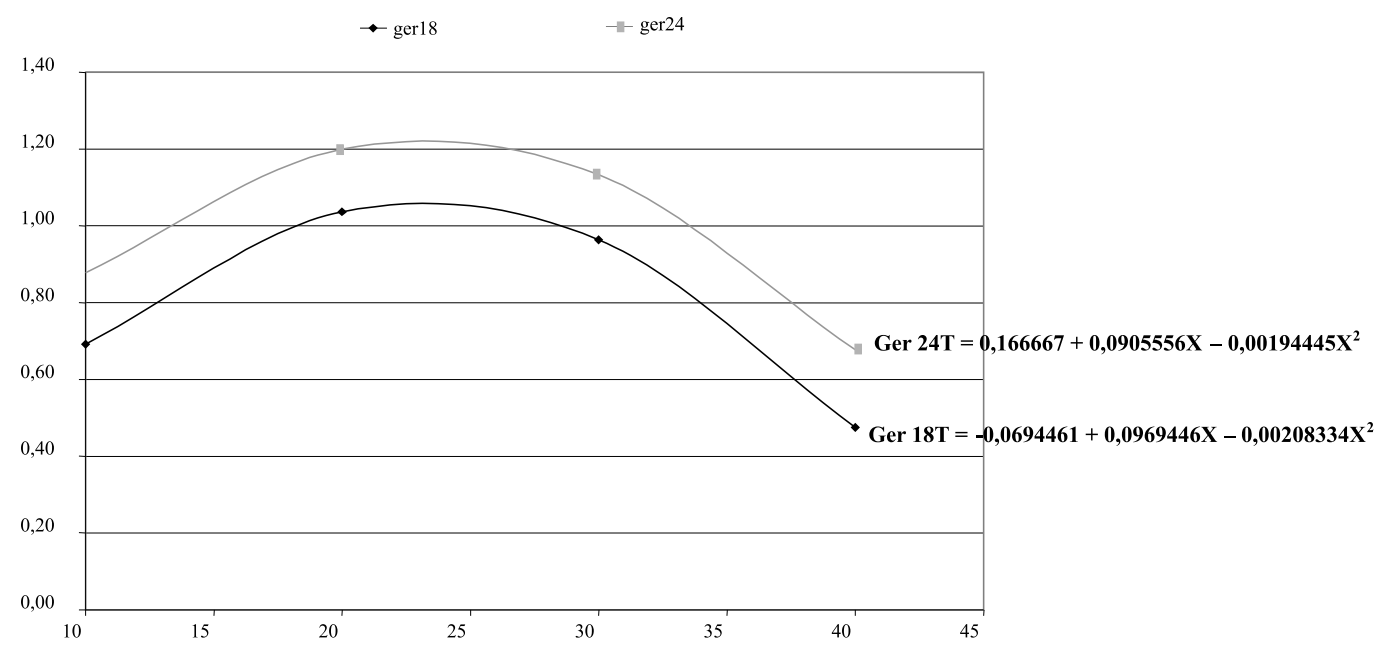

Figura 3 - Médias ajustadas de sementes germinadas de Swietenia macrophylla, aos 18 e 24 dias após a semeadura, em função dos tempos de desinfestação.

Figure 3 - Adjusted averages of germinated seeds of Swietenia macrophylla at 18 and 24 days after sowing, in function of the times of desinfestação.

Em relação à posição da semente no momento da semeadura, pode-se observar que houve diferença significativa do número de sementes germinadas nas avaliações com 24 e 30 dias após a semeadura, com as maiores médias de germinação ocorrendo nas sementes colocadas na posição 2 , ou seja, quando a parte côncava da semente ficou voltada para baixo. Resultados similares foram observados por Tito e Rodriguez (1988), que constataram que as sementes de mogno semeadas na posição horizontal apresentaram maior índice de germinação em condições de viveiro.

Ao estudar a posição de semeadura de mogno em condições de casa de vegetação, Mondala (1977) notou que, quando as sementes foram semeadas com 
o eixo embrionário perpendicular ao solo, a porcentagem de germinação foi maior. Autores como Noltee (1926) e Lamb (1966) também relataram que as sementes de mogno devem ser semeadas na posição horizontal com o embrião perpendicular ao solo ou voltado para cima. Porém, Neil (1987) observou que, ao colocar as sementes de mogno em posição vertical, as plântulas apresentaram uma redução quanto à deformidade do sistema radicular.

A interação entre o tempo de desinfestação e a concentração de hipoclorito de sódio somente foi significativa na germinação das sementes aos 18 dias após a semeadura (Quadro 3).

Quando se utilizou hipoclorito de sódio nas concentrações de 0 e $2,5 \%$, não foram observadas diferenças significativas nos diferentes tempos de desinfestação, mas, quando a concentração do hipoclorito de sódio foi igual a $5 \%$, a maior porcentagem de germinação ocorreu aos 30 minutos de embebição. Entretanto, ao avaliar o número de sementes germinadas aos 18 dias nos tempos de desinfestação utilizados, observou-se que as maiores médias ocorreram nas sementes desinfestadas com hipoclorito de sódio 5,0\%, nos tempos de 20 e 30 minutos de desinfestação, e naquelas desinfestadas com hipoclorito de sódio 2,5\%, com desinfestação por 10,30 e 40 minutos.

Não foram observadas interações significativas entre o hipoclorito de sódio e a posição de semeadura, nem entre o tempo de desinfestação e a posição de semeadura, na capacidade de germinação das sementes aos 12, 18, 24 e 30 dias após a semeadura.

\section{CONCLUSÕES}

Nas condições experimentais adotadas, os resultados permitem as seguintes conclusões:

$\S$ As sementes desinfestadas em 2,5 e $5,0 \%$ de hipoclorito de sódio por 30 e 20 minutos, respectivamente, na posição 2 (com a parte côncava voltada para baixo) apresentaram maior porcentagem de germinação.

$\S$ Os tratamentos anteriores resultaram em índices baixos de contaminação por bactérias e fungos.

$\S$ A posição das sementes (com a parte côncava voltada para baixo) na semeadura, no meio de cultura, influenciou positivamente a eficiência de germinação.

\section{REFERÊNCIAS BIBLIOGRÁFICAS}

ANDRADE, M.W. et al. Micropropagação da Aroeira (Myracrodruon urundeuva Fr. All).

Revista Ciência e Agrotecnologia, v. 24, n. 1, p. 174-180, 2000.

CARVALHO, P. E. R. Espécies florestais brasileiras: recomendações silviculturais, potencialidades e uso da madeira. Brasília: EMBRAPA/CNPF, 1994. 640 p

CORDER, M. P. M.; BORGES JUNIOR, N. Desinfestação e quebra de dormência de sementes de Acacia mearnsii de Wil. Ciência

Florestal, v. 9, n. 2, p. 1-7, 1999.

FAIAD, M. G. R. et al. Efeito do hipoclorito de sódio sobre a qualidade fisiológica e sanitária de sementes de Commiphora lepthopholoeos (Mart.) J. B. Gillet. Revista Brasileira de Sementes, v. 19, n. 1, p. 14-17, 1997.

KALIL FILHO, A. N. et al. A Micropropagação do mogno (Swietenia macrophylla): desinfestação e germinação. In: SIMPÓSIO INTERNACIONAL SOBRE ECOSSISTEMAS FLORESTAIS - FOREST 2000, 6., 2000. Porto Seguro. Anais... Porto Seguro: [s.n.], 2000. p. Bio1013.

LAMB, F. B. Mahogany of tropical america: its ecology and management. Ann Arbor: University of Michigan Press, 1966. 220p.

LEMOS, O. F. et al. Produção de plântulas para micropropagação do mogno (Swietenia macrophylla King). In: CONGRESSO NACIONAL DE GENÉTICA, 44., 1998, Águas de Lindóia.

Resumos... Águas de Lindóia: 1998. p. 216.

LOPES, S. C. Micropropagação de mogno (Swietenia macrophylla). 2000. 53f. Dissertação (Mestrado em Ciências) - Universidade Federal de Pelotas, Pelotas, 2000.

MONDALA, C. A. Depth and position of sowing large-leaf Mahogany seeds. Sylvatrop, v. 2, n. 2, p. 131-137, 1977.

MORAES, E. C. Informações pessoais, 2002. 
MURASHIGE, T.; SKOOG, F.A. A revised medium for rapid growth and bioassays with tobacco tissue cultures. Physiologia Plantarum, v. 15, p. 473-497, 1962.

NEIL, P. E. Swietenia macrophylla (mahogany) in Vanuatu. Commonwealth Forest Review, v. 66, n. 3, p. 255-264, 1987.

NOLTEE, A. C. Swietenia mahogany and Swietenia macrophylla. In: -----. Indonesian forestry abstracts 1982. Wageningen: [s.n.], 1926: n. 735.

PARRAGUIRRE, C. L.; CAMACHO, M. F.

Velocidad de germinación de veintiuno espécies forestales tropicales. Revista Ciência

Forestal em México, v. 17, n. 72, p. 3-26, 1992.
PRADHAN, C. et al. Propagation of Dalbergia sissoo Roxb. through in vitro shoot proliferation from cotyledonary nodes. Plant Cell Reports, v. 18, p. 122-126, 1998.

SKIRVIN, R. M. Fruticulture crops. In: CONGER, $B$. V. Cloning agricultural plants via in vitro techniques. Boca Raton: CRC Press, 1981. p. 51-139.

TITO, B.V.; RODRÍGUEZ, M. Estudio silvicultural preliminar de la caoba en la zona de Tingo María. In: --_--. Avances de la silvicultura en la Amazonia peruana. Lima: República del Perú, Instituto Nacional de Desarrollo, 1988. (Documentos de Trabajo, 11). 